\title{
EXAMINATION OF THE MATURITY DIFFERENCE OF STOCK COSTS IN TERMS OF TAX PROCEDURE LAW, TAS 2 FINANCIAL REPORTING STANDARD FOR LARGE AND MEDIUM SIZE ENTERPRISES
}

\author{
DOI: 10.17261/Pressacademia.2018.915 \\ PAP- V.7-2018(68)-p.356-358
}

\section{Kadriye Arisoy}

Mehmet Akif Ersoy University, Burdur, Turkey.

arsykdry@gmail.com, ORCID: 0000-0002-7659-5464

To cite this document

Arisoy, K. (2018). Examination of the maturity difference of stock costs in terms of Tax Procedure Law, TAS 2 financial reporting standard for large and medium size enterprises. PressAcademia Procedia (PAP), V.7, p.356-358.

Permemant link to this document: http://doi.org/10.17261/Pressacademia.2018.915

Copyright: Published by PressAcademia and limited licenced re-use rights only.

\section{ABSTRACT}

Purpose- The difference between the tax procedural law and current standards that guide the application of the cost of purchasing in the intended stocks of work.

Methodology- The method of study in the literature as tax procedure law and the provisions of the items included in the standard literature search was conducted to be addressed.

Findings- In the survey, both the tax legislation and the TAS 2 Inventories Standard and financial reporting standart of large and medium size enterprises differend in their application to maturity differences. It has been found that the approach of tax laws and standards to borrowing costs is different.

Conclusion- Located term differences Tax Procedure Law in purchase cost of borrowing coverage on purchases for stocks in pencil assets Property, Turkey accounting standards and enacted in January 2018 financial reporting standards for large and medium-sized enterprises are handled differently. Turkey accounting standards and financial reporting standards for large and medium-sized enterprises is distinguished from the product cost and is regarded as an element of financing. On the other hand, the Tax Procedural Law incorporates maturity differences into its inventory costs. The differences of the maturity differences regarding the cost of purchasing the working stocks in terms of tax legislation and standards are discussed in comparison.

Keywords: Tax Procedure Law, TAS, financial reporting standard for large and medium size enterprises (BOBi FRS), stocks.

JEL Codes: M40, M41, M42

\section{STOK SATIN ALMA MALIYETLERINDE VADE FARKININ VERGI USUL KANUNU, TMS 2 VE BOBI FRS AÇISINDAN INCELENMESI}

\section{ÖZET}

Amaç- Çalışmanın amacı stokların satın alma maliyetlerinde uıygulamaya yön veren Vergi Usul Kanununu ve mevcut standartlar arasındaki farklılıkların ortaya konulmasıdır.

Yöntem- Çalışmanın yöntemi olarak literatürde vergi usul kanunu hükümleri ve standartlarda yer alan maddeler ele alınıp literatür araştırması yapılmıştır.

Bulgular- Araştırmada hem vergi mevzuatının hem de TMS 2 Stoklar Standardı ve BOBi FRS 'nin vade farklarına yönelik olarak uygulamalarının farklıığı ortaya koyulmuştur. Vergi kanunlarının ve standartların borçlanma maliyetlerine yaklaşımının farklı olduğu görülmüştür.

Sonuç- İşletmelerin varlık kalemlerinden stoklara yönelik satın alımlarda borçlanma maliyeti kapsamı içerisinde yer alan vade farkları Vergi Usul Kanunu, Türkiye Muhasebe Standartları ve Ocak 2018'de yürürlüğe giren Büyük ve Orta Boy İşletmeler İçin Finansal Raporlama Standartlarında farkl olarak ele alınmaktadır. TMS ve BOBi FRS'de stoklara ilişkin vade farkları mamul maliyetinden ayrıştırılıp finansman unsuru olarak değerlendirilmektedir. Öte yandan Vergi Usul Kanunu vade farklarını stok maliyetlerine dahil etmektedir. Çalışmanın amacı stokların satın alma maliyetleri ile ilgili olarak vade farklarının vergi mevzuatı ve standartlar açısından karşılaştırmalı olarak ele alınıp farklılıkların ortaya konulmasıdır.

Anahtar Kelimeler: VUK, TMS, BOBi FRS, stoklar.

JEL Kodları: M40, M41, M42 


\section{Giriş}

Uluslararası Muhasebe Standartları Kurulu (IASB) stoklara yönelik muhasebe uygulamalarına IAS 2'de yer vermiştir. Türkiye'de ise Türkiye Muhasebe Standartları Kurulu (TMSK) tarafından yayımlanan ve IAS 2' nin çevirisi olan Türkiye Muhasebe Standartları Stoklar Standardı (TMS 2) kullanılmaktadır. Söz konusu TMS 2 Stoklar Standardında stoklara ilişkin muhasebe düzenlemelerine yer verilmektedir. Söz konusu TMS 2 Stoklar standardı ile stokların değerlemesine yönelik düzenlemeler önemli hale gelmektedir. Stokların değerlemesinde son derece önem arz eden konular arasında borçlanma maliyetlerinden vade farkı, kur farkı ve faiz giderlerinin nasıl izleneceğidir. Çalışmada amaçlanan stokların satın alımlarında vade farkları ile ilgili olarak uygulamaya yön veren Vergi Usul Kanunu ile standartların hükümlerinin karşılaştırmalı olarak incelenmesi ve farklılıkların ortaya konulabilmesidir.

\section{VERGI USUL KANUNU, TMS 2 STOKLAR STANDARDI VE BOBI FRS AÇISINDAN STOK MALIYETLERINDE VADE FARKLARI}

Vergi Usul Kanunu değerlemede tek bir ölçek kullanılması ilkesini benimsemektedir. Doğrudan vergi matrahının tespitine yönelik olan değerlemede iktisadi kıymet için hangi değerleme ölçüsünün kullanılacağı kanunda açık olarak belirtilmiştir. Ve bu doğrultuda da değerleme ölçüsü ile ilgili tercih hakkı tanınmamıştır (Ergin, 2016: 15). VUK 274. maddesine göre ; satın alınan veya imal edilen emtia maliyet bedeli ile değerlenir (VUK, md:274). Maliyet bedeli ise kanunda şu şekilde tanımlanmıştır ; "Bir iktisadi bir kıymetin iktisap edilmesi veyahut değerinin artırılması münasebetiyle yapılan ödemelerle buna bağlı olarak yapılan her türlü giderlerin toplamıdır " (VUK ,md: 262). Stokların değerleme ölçüsü VUK 274.maddesinde maliyet bedeli olarak belirlenmiş olup değerleme; satın alınan emtianın değerlemesi (VUK, 274 md.), imal edilen emtianın değerlemesi (VUK, 275 md.), zirai mahsullerin ve hayvanların değerlemesi (VUK, md. 276- 277) ve değeri düşen malların değerlemesi (VUK, md. 278) şeklinde ayrı başlıklar altında incelenmiştir (Elitaş vd, 2010: 89). Çalışmada satın alınan mallara ilişkin olarak vade farklarının durumu ele alınmıştır.

Yurt içinden satın alınan emtiada maliyet bedelinin ana unsurları şunlardır; (Öngen, 2000: 147)

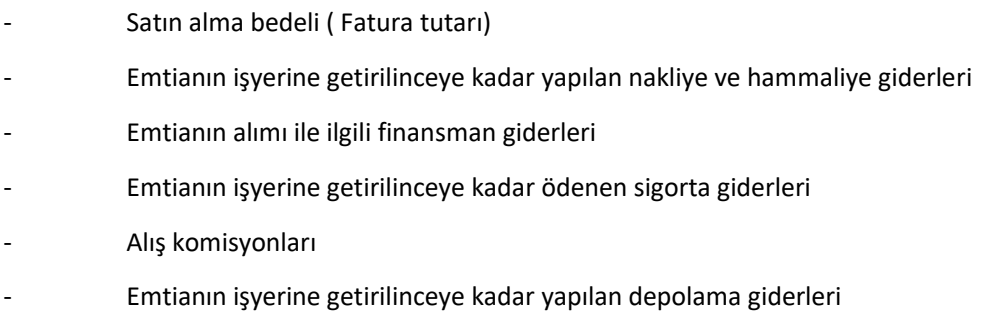

Vade farkı malın satın alım bedelinin peşin ödenmemesi nedeniyle peşin malın bedeline ilaveten yapılan ödemelerdir. İlaveten yapılan bu ödemeler fatura tutarına dahil edilebileceği gibi sonradan doğduğu için ayrı olarak fatura edilmiş olabilir. Vade farkları doğrudan mal alışı ile alakalı olup malın maliyetine dahil edilir (Öztürk, 2007: 187) Vergi mevzuatına göre mal satın alımında vade farkı alış bedeli içerisinde yer almakta mal bedelinden ayrıştırılmamaktadır. Mal alışı esnasındaki ödemelerin gecikmesinden kaynaklı olan vade farkları emtianın maliyetine dahil edilmeden dönem gideri olarak muhasebeleştirilir. Ödemelerin gecikmesi sonucu ortaya çıkan vade farkları konusunda VUK ve TMS 2 Stoklar Standardı arasında bir uygulama farkı yoktur (Avcı ve Avcl, 2016: 80).

TMS 2 Stoklar Standardının 10. maddesine göre; işletmenin stokları elde etmesi ve satılabilir duruma getirebilmesi amacıyla katlandığı maliyetler aşağıdaki gibi sınıflandırılabilir ; ( Demirel, 2012: 156)

1) Satın Alma Maliyetleri (Hammadde, Yardımcı Malzeme, İşletme Malzemesi, Ticari Mal vb.),

2) Dönüştürme Maliyetleri (Direkt İşçilik, Sabit ve Değişken Genel Üretim Giderleri)

3) Diğer Maliyetler (Araştırma-Geliştirme Maliyetleri ve Tasarım Maliyetleri)

TMS 2 stoklar standardı ile uygulamaya getirilen yeniliklerde en önemlisi satın alma maliyetlerinde vade farklarının muhasebeleştirilmesidir. Standarda göre vade farkları stok maliyetlerine dahil edilmeyerek faiz gideri olarak muhasebeleştirilmelidir (Özerhan ve Yanık, 2012: 127). TMS 2 stoklar standardında ilgili madde şu şekilde açıklanmıştır; "Bir işletme stokları vadeli ödeme koşuluyla almış olabilir. Anlaşma, peşin alım fiyatı ile ödenen fiyat arasında bir fark olan finansman unsuru içerdiği takdirde, bu unsurlar finanse edildiği dönemde faiz gideri olarak muhasebeleştirilir" ( TMS 2 , md.18). Uygulamada vade farkından doğan fiyat farkının stok maliyetine dahil edilmemesinin amacı stokların satın alımı sırasında oluşan faiz maliyetinin stok maliyetine dahil edilerek stokların olduğundan daha yüksek değerlenmesini önlemektir( Oğuzhan, 2012: 56).

Satın alımlara yönelik vade farkları 1 Ocak 2018'de yürürlüğe giren BOBi FRS'de TMS 2 stoklar standardından farklı olarak ele alınmıştır. ВОВі FRS Bölüm 6'da vade farklarına yönelik açıklama şu şekilde verilmiştir; "Bir yıl veya daha kısa vadeli bir ödeme karşılığında satın alınan stoklar, vade farkı ayrıştırılmaksızın, ödenen veya ödenmesi beklenen nakit tutar üzerinden ölçülür. Bir yıldan uzun vadeli bir ödeme karşılığında satın alınan stoklar ise, vade farkı ayrıştırılarak peşin fiyat üzerinden (diğer bir ifadeyle işletme peşin ödeme yapmış olsaydı ödeyeceği fiyat üzerinden) ölçülür. Bu kapsamda bir stokun bir yıldan daha uzun vadeli bir ödeme karşılığında satın alınması durumunda vade farkı tutarı, "Finansal Araçlar ve Öz kaynaklar" bölümünün 9.14 - 9.19 paragrafları uyarınca etkin faiz yöntemine göre hesaplanarak, faiz gideri olarak muhasebeleştirilir " (BOBi, FRS, md:6.8). TMS 2 stoklar standardı ile BOBi FRS bölüm 6 arasındaki en önemli farklılıklardan birisi stokların satın alınmasında vade farklarının ayrıştırılmasıdır. TMS 2'de tüm vade farkları ayrıştırılırken; BOBi FRS stoklar bölümünde sadece bir yıldan uzun vadeli alımlarda vade farkı ayrıştırılmakta ve faiz gideri olarak muhasebeleştirilmekte, bir yıldan kısa vadeli alımlarda ise vade farkı ayrıştırılmamaktadır (Gençoğlu,2017: 12). Stoklarla ilgili borçlanma maliyetleri oluştukları dönemde kâr veya zarara yansıtılır. 
Ancak standardın "Borçlanma Maliyetleri" bölümünün 2. paragrafı gereğince üretilmesi normal şartlar altında bir yıldan daha uzun süren stoklar için katlanılan borçlanma maliyetleri satışa hazır hale geldiği tarihe kadar stokun maliyetine dâhil edilir (BOBi FRS, md: 6.9). Bu durum TMS 2'de (TMS 23 Borçlanma Maliyetleri standardına atıfta bulunarak) özellikli varlık niteliğinde olan stoklar için geçerli olup bu tür stoklar tamamlanana kadar ilgili borçlanma maliyetleri stoğun maliyetine eklenmekte, sonradan ortaya çıkan borçlanma maliyetleri gider olarak kaydedilmektedir (Ataman ve Cavlak 2017: 160).

Tablo 1: Vade Farklarının VUK, TMS 2 Stoklar Standardı ve BOBi FRS Açısından Karşılaştırııması

\begin{tabular}{|l|l|l|}
\hline VERGi USUL KANUNU (VUK) & TMS 2 Stoklar Standardı & BOBi FRS \\
\hline $\begin{array}{l}\text { Vade farkları stok maliyetine dahil } \\
\text { edilir. }\end{array}$ & $\begin{array}{l}\text { Vade farkları stok maliyetinden } \\
\text { ayrıştırılarak dönem gideri olarak } \\
\text { kaydedilir. }\end{array}$ & $\begin{array}{l}\text { Vade süresi bir yıldan uzun satın alımlarda vade } \\
\text { farkı stok maliyetinden ayrıştırılıp ve dönem gideri } \\
\text { olarak kaydedilir. Bir yıldan kısa vadeli alımlarda } \\
\text { vade farkı ayrıştırılmamaktadır. }\end{array}$ \\
\hline
\end{tabular}

\section{SONUÇ}

Uluslararası muhasebe standartları ile birlikte stokların değerlemesi önem kazanan konular arasına girmektedir. Söz konusu standartlar mevcut uygulamadaki muhasebe sistemimize bir takım değişiklikleri de birlikte getirmektedir. Bu farklılıklardan birisi de stok değerlemesi konusuna ilişkin olarak satın alımlarda vade farklarına yönelik düzenlemelerdir. TMS 2 stoklar standardı stok alımlarında vade farklarını satın alma maliyetlerine dahil etmemektedir. Vade farkları ayrı bir finansman unsur olarak değerlendirilmekte ve dönem gideri olarak kaydedilmektedir. Kamu gözetimi kurumu (KGK) tarafından yayınlanan Büyük ve Orta Boy İşletmeler İçin Finansal Raporlama Standartları ile birlikte uzun vadeli stok alımlarında vade farkı satın alma maliyetinden ayrıştırılmaktadır. Dolayısıyla burada TMS 2 Stoklar Standardından farklı bir düzenleme getirildiği görülmektedir. Söz konusu bu standartların vadeli alışlarda satın alma maliyetleri içerisinde vade farklarına yönelik düzenlemelerinin farklı olduğu görülmektedir. Öte yandan mevcut uygulamalara yön veren Vergi Usul Kanununda ise ister uzun ister kısa vadeli alımlarda vade farkının stok maliyetlerine dahil edilmekte olduğu ve standartların düzenlemelerinden farklı olduğu anlaşılmaktadır.

\section{KAYNAKLAR}

Ataman, B., Cavlak, H. (2017). Büyük ve orta boy işletmeler için finansal raporlama standardı (BOBi FRS) ile tam set türkiye muhasebe ve türkiye finansal raporlama standartlarının (TMS/TFRS) karşılaştırılması. Finans Ekonomi ve Sosyal Araştırmalar Dergisi, S.3, 153-168.

Avcı, Ö., Avcı, A. (2016). Vade farkı, kur farkı ve kredi faizlerinin türkiye muhasebe standartları ve vergi usul kanunu kapsamında değerlendirilmesi'. Mali Çözüm, S.134, 75-90.

Bahadır, O. (2012). Stoklarda değerleme: UFRS/TFRS ve vergi mevzuatı açısından. Mali Çözüm Dergisi, S.109, 51-67.

Gençoğlu, Ü. (2017). Temel konularda BOBi FRS ve TMS/TFRS karşılaştırması. Muhasebe Ve Finansman Dergisi, S. 76, 1-24.

Erkan, M., Elitaş, C., Ceran, Y. (2010). Dönem sonu muhasebe işlemleri (TMS /TFRS Uyumlu). Ekin Basım Yayın Dağıtım.

Ergin, N. (2016). Vergi mevzuatı ile TMS /TFRS'nin değerleme ölçüleri açısından karşılaştırılması. Vergi Dünyası, S. 418, 9-20.

Demirel, N. (2009). Stoklara ilişkin türkiye muhasebe standartlarının sermaye piyasası kuruluna kayıtlı halka açık anonim şirketlerde uygulama örnekleri. Yüksek Lisans Tezi.

Maliye ve Gümrük Bakanlığı. (1995). 238 sıra nolu vergi usul kanunu genel tebliği. Ankara: Resmi Gazete (22218 Sayılı).

Kamu Gözetimi Kurumu. Türkiye muhasebe standardı $\quad$ (TMS 2 2) stoklar (http://kgk.gov.tr/Portalv2Uploads/files/DynamicContentFiles/T\%C3\%BCrkiye\%20Muhasebe\%20Standartlar\%C4\%B1/TMSTFRS2016Seti/T MS2.pdf).

Kamu Gözetimi Kurumu. Büyük ve orta boy işletmeler için finansal raporlama standardı (BOBi FRS). (http://kgk.gov.tr/Portalv2Uploads/files/PDF\%20linkleri/BOB\%C4\%B0\%20FRS.pdf).

Özerhan, Y., Yanık, S. (2012). Açıklamalı ve örnek uygulamalı Türkiye muhasebe standartları Türkiye finansal raporlama standartları. TÜRMOB Yayınları.

Öztürk, B., Öğrendik, G. (2007). Dönem sonu muhasebe ve vergi uygulamaları. Maliye ve Hukuk Yayınları.

Öngen, S. (2000). Vergi muhasebesi. Yaklaşım Yayıncılık, Ankara. 